Bond University

Research Repository

\title{
Can simulation foster resilience in medical students?
}

Yates, Natasha; Purdy, Eve; Braganza, Shahina; Alsaba, Nemat; Spooner, Anne; Smith, Jane; Brazil, Victoria

Published in:

BMJ Simulation and Technology Enhanced Learning

DOI:

10.1136/bmjstel-2020-000622

Licence:

CC BY-NC

Link to output in Bond University research repository.

Recommended citation(APA):

Yates, N., Purdy, E., Braganza, S., Alsaba, N., Spooner, A., Smith, J., \& Brazil, V. (2021). Can simulation foster resilience in medical students? BMJ Simulation and Technology Enhanced Learning, 7(1).

https://doi.org/10.1136/bmjstel-2020-000622

\section{General rights}

Copyright and moral rights for the publications made accessible in the public portal are retained by the authors and/or other copyright owners and it is a condition of accessing publications that users recognise and abide by the legal requirements associated with these rights.

For more information, or if you believe that this document breaches copyright, please contact the Bond University research repository coordinator. 
This article has been accepted for publication in BMJ Simulation and Technology Enhanced Learning following peer review, and the Version of Record can be accessed online at https://doi.org/10.1136/bmjstel-2020-000622

(c) BMJ Publishing Group Ltd

\section{Title Page:}

\section{Can simulation foster resilience in medical students?}

Dr Natasha Yates, MBBS; FRACGP. Assistant Professor, Deputy Lead of General Practice, HSM Faculty, Bond University, Gold Coast, Australia nyates@bond.edu.au

Dr Eve Purdy, MD. Emergency Physician, Department of Emergency Medicine, Queen's University, Kingston, Ontario Canada epurdy@qmed.ca

Dr Shahina Braganza, MBBS (Hons); BMedSci, FACEM. Emergency Physician, Gold Coast Health, Honorary Adjunct Associate Professor, Department of Health Sciences and Medicine, Bond University, Gold Coast, Australia shahina.braganza@gmail.com

Dr Nemat Alsaba, MBBS, FACEM. Emergency Physician, Gold Coast University Hospital, Assistant Professor in Medical Education and Simulation, Deputy Director Bond University Simulation program, HSM Faculty, Bond University, Gold Coast, Australia nalsaba@bond.edu.au

Dr Anne Spooner, MBBS. General Practitioner, Practitioner Theme Lead, HSM Faculty, Bond University, Gold Coast, Australia aspooner@bond.edu.au

Dr Jane Smith, MBBS, FRACGP, Grad DipFM,MHS, FAICD, Associate Professor, Head of Discipline of General Practice, HSM Faculty, Bond University, Gold Coast, Australia jsmith@bond.edu.au

Dr Victoria Brazil MBBS, FACEM, MBA. Professor of Emergency Medicine, Director Bond University Simulation program, HSM Faculty, Bond University, Gold Coast, Australia vbrazil@bond.edu.au

Corresponding author details: Natasha Yates nyates@bond.edu.au, HSM Faculty, Bond University, 4229, Qld, Australia 
This article has been accepted for publication in BMJ Simulation and Technology Enhanced Learning following peer review, and the Version of Record can be accessed online at https://doi.org/10.1136/bmjstel-2020-000622

(C) BMJ Publishing Group Ltd

\section{Can simulation foster resilience in medical students?}

\section{Summary:}

Resilience is considered to be "a mindset and skill set that can be nurtured into a stronger and more effective attribute" (1). Whether and how it can be nurtured in medical students is a subject of interest for medical educators $(1,2)$. Little is known about how physicians develop resilience (3). While some interventions show promise (4), resilience training in medical education is not well studied. We aimed to develop a teaching intervention with high acceptability to undergraduate medical students, which would allow exposure to challenges in a controlled, psychologically safe environment, and might enhance their resilience. Simulation-based education provided opportunities for carefully designed scenarios and debriefing by trained facilitators. Structured debriefing enabled participants to recognise and discuss stressful situations, as well as increase their connection with each other and with their teachers. These factors have been found to enhance resilience in other contexts (5).

Participants' impressions were explored qualitatively, and suggest that simulation can encourage reflection on the non-technical skill of resilience, provided there is careful design and debriefing of the simulation activity.

\section{The project:}

In this project we sought to understand whether simulation can be used as a tool to explore and enhance resilience in medical students. 
This article has been accepted for publication in BMJ Simulation and Technology Enhanced Learning following peer review, and the Version of Record can be accessed online at https://doi.org/10.1136/bmjstel-2020-000622

(C) BMJ Publishing Group Ltd

Enhancing resilience is recognised as a worthy goal for a variety of reasons, including defensive (protection against mental health struggles), proactive (to optimize productivity), and as an important aspect of professional identify formation (6).

The challenge for medical educators is that building resilience requires exposure to a trial which is sufficient to cause growth, but not so difficult that it causes harm. We designed simulation exercises to provide stimulus for fostering resilience. Recognising that excessive trauma will lower resilience, whilst mild trauma may have no effect upon it, using simulation as an experiential learning modality was not without risk. This was carefully considered in our design and follow up, and ethics approval was obtained as part of the accountability structure of the project.

Participants were final year medical students in an eight-week critical care rotation at Bond University, Gold Coast, Australia in 2018. Of note, these students had significant prior exposure to simulation in their medical curriculum. Groups of three or four students were placed in a challenging simulated scenario (see Figure scenario 1).

Carefully selected facilitators debriefed each group. Facilitators were experienced clinicians and educators with specific training and experience in simulation debriefing. They encouraged discussion around active coping and reflective practice. Participants were then invited to re-enter the simulation and apply what they had just explored in the debriefing session. The scenario was changed subtly but core challenges were similar (Figure Scenario 2). The second debriefing again focused on active coping and reflective practice. 
This article has been accepted for publication in BMJ Simulation and Technology Enhanced Learning following peer review, and the Version of Record can be accessed online at https://doi.org/10.1136/bmjstel-2020-000622

(C) BMJ Publishing Group Ltd

Please note that these were both fictional scenarios and do not describe information regarding actual patients or nurses. Any resemblance to real persons, living or deceased, is a coincidence.

After the simulations, four participating students discussed their learning and experiences in semi-structured phone interviews. Recordings were transcribed verbatim and de-identified prior to analysis.

Four main themes and two subthemes were identified by the research team:

\section{Theme 1: Differing perspectives as a source of conflict}

Differing perspectives within the healthcare system were identified by participants as key sources of conflict. Disagreements were described between doctors, within teams, with other healthcare providers, and with patients. Conflict was not always overt or dramatic, but was sufficient to cause distress.

"Most of the time it's day to day, little, tiny things where certain people's priorities don't quite coincide with the doctor's priorities and it's just working through that."

\section{Theme 2: Shifting perspectives to resolve conflict}

Being willing and able to shift perspectives was seen as key to processing conflict and coping with challenges. Two facilitating subthemes were identified: Listening and talking, and Experiencing. 
This article has been accepted for publication in BMJ Simulation and Technology Enhanced Learning following peer review, and the Version of Record can be accessed online at https://doi.org/10.1136/bmjstel-2020-000622

(c) BMJ Publishing Group Ltd

\section{Subthemes:}

a. Listening and talking "I also learnt the power of just listening to people." "Sometimes you don't have the answer but if you just let them talk, then sometimes that helps a lot."

b. Experiencing "I think we need more of these kind of simulations...Until you actually put yourself in a scenario and work through it yourself, I don't think you ever quite grasp it."

\section{Theme 3: Validating experiences and coping strategies}

The creation of experience was necessary to shift perspectives. Students described both their personal experiences of difficulty and their learning through the experiences of others. "It was valuable to see that all doctors experience these scenarios..."

\section{Theme 4: Outside and Inside - tension between the external and internal self}

Students reflected on the importance of paying attention to emotions; not over-riding them but allowing them to inform decisions and behaviours in a constructive way. The challenge of managing internal conflict while maintaining external professionalism was also described. "We had to kind of think about why we said those things, and, yes, that's something we're not used to doing. So, I found it helpful."

General feedback suggested these scenarios held high face validity for students and offered sufficient emotional and social load to recognize, manage and, reflect upon how they cope with confronting circumstances. 
This article has been accepted for publication in BMJ Simulation and Technology Enhanced Learning following peer review, and the Version of Record can be accessed online at https://doi.org/10.1136/bmjstel-2020-000622

(C) BMJ Publishing Group Ltd

The results demonstrate promising potential for simulation to help medical students to foster resilience, through semi-structured debriefing and deliberate practice.

Next steps will be further exploration with larger numbers of participants, and to develop guidelines and training for faculty, ensuring optimal learning outcomes and psychological safety for this type of simulation exercise. The recommendations offered in this commentary may prove useful in the development of a theoretical framework for further exploration.

\section{Funding statement:}

This research received no specific grant from any funding agency in the public, commercial or not-for-profit sectors

\section{Competing interests statement:}

All authors declare no conflicts of interest and have nothing to disclose

\section{Contributorship statement:}

NY and VB designed the study and obtained ethical approval

NY, AS and JS recruited and consented participants and conducted pre-intervention analysis

$V B, S B$ and $N A$ conducted the intervention and post-intervention quantitative analysis

EP conducted the post-intervention interviews

NY, VB and EP analyzed and interpreted the quantitative participant data

NY, VB, EP, NA and SB analysed and interpreted the qualitative participant data 
This article has been accepted for publication in BMJ Simulation and Technology Enhanced Learning following peer review, and the Version of Record can be accessed online at https://doi.org/10.1136/bmjstel-2020-000622

(c) BMJ Publishing Group Ltd

All authors read and approved the final manuscript

\section{Acknowledgements}

1. The Harvard Macy program for educators in the health professions for peer review of the study design

2. Christine Sly and Pippa Eaton for their logistical support for delivery of the simulation program, and student liaison during the study

3. Schyler Waynforth and David Waynforth for support with results analysis

\section{References}

1. Howe A, Smajdor A, Stockl A. Towards an understanding of resilience and its relevance to medical training. Med Educ. 2012;46(4):349-56.

2. Epstein RM, Krasner MS. Physician resilience: what it means, why it matters, and how to promote it. Acad Med. 2013;88(3):301-3.

3. LaDonna KA, Ginsburg S, Watling C. Shifting and Sharing: Academic Physicians' Strategies for Navigating Underperformance and Failure. Acad Med. 2018;93(11):1713-8.

4. Chmitorz A, Kunzler A, Helmreich I, Tuscher O, Kalisch R, Kubiak T, et al. Intervention studies to foster resilience - A systematic review and proposal for a resilience framework in future intervention studies. Clin Psychol Rev. 2018;59:78-100.

5. Ziegelstein RC. Creating Structured Opportunities for Social Engagement to Promote Well-Being and Avoid Burnout in Medical Students and Residents. Acad Med. 2018;93(4):537-9 

and the Version of Record can be accessed online at https://doi.org/10.1136/bmjstel-2020-000622

(c) BMJ Publishing Group Ltd

6. Wald HS. Professional identity (trans)formation in medical education: reflection, relationship, resilience. Acad Med. 2015;90(6):701-6. 